\title{
The structure and mechanical properties of AIMg5Si2Mn alloy after surface alloying by the use of fiber laser
}

\author{
Wojciech Pakieła ${ }^{1} \cdot$ Tomasz Tanski $^{1} \cdot$ Mirosława Pawlyta $^{1} \cdot$ Katarzyna Pakieła $^{1} \cdot$ Zbigniew Brytan $^{1} \cdot$ Marek Sroka $^{1}$
}

Received: 25 September 2017 / Accepted: 25 December 2017 / Published online: 21 February 2018

(c) The Author(s) 2018. This article is an open access publication

\begin{abstract}
Laser surface treatment is successfully applied to increase hardness as well as corrosion and wear resistance in light alloys such as aluminum or magnesium. The laser surface remelting also can be used to repair superficial cracks, voids or porosity caused by the mechanical impact, metallurgical process as well as the corrosive environment on the surface of the aluminum alloy. The purpose of this paper was to investigate the influence of a fiber laser surface treatment on the structure and properties of the EN AC AlMg5Si2Mn alloy. The goal of this investigation was to increase the hardness and improve tribological properties of the aluminum alloy surface as a result of the conducted laser surface treatment. During laser processing, the top surface of the aluminum alloy was enriched with $\mathrm{Cr}$ and $\mathrm{Ni}$ particles. The grain size of the applied particles was approximately about $60-130 \mathrm{~m}$. The $\mathrm{Cr}-\mathrm{Ni}$ powder has been introduced in the molten pool using vacuum feeder at a constant rate of $4.5 \mathrm{~g} / \mathrm{min}$. For surface remelting we used square laser beam at a size $3 \times 3 \mathrm{~mm}$ and with the power of $3.0 \mathrm{~kW}$. The linear laser scan rate of the beam was set at $0.5 \mathrm{~m} / \mathrm{min}$. Argon was used to protect the liquid metal alloy during surface treatment. Application of the laser treatment on aluminum alloy has enabled to obtain much harder as well as better wear resistant material compared to the untreated EN AC AlMg5Si2Mn.
\end{abstract}

\section{Introduction}

Constantly growing expectations for modern engineering materials compel the search for new solutions. Advanced design requires a simultaneous combination of both low density, high corrosion resistance, good abrasion resistance and high strength properties. The engineering materials requirements for advanced constructions make it very often that engineers are forced to use more advanced technology [1-7]. To improve the mechanical properties of metal alloys such as aluminum and magnesium as well as various type of steels (tool steels, stainless steels), thermal and chemical surface treatment are used [8-14]. The latest technologies include, among others, various technologies of laser surface

Wojciech Pakieła

wojciech.pakiela@polsl.pl

Tomasz Tanski

tomasz.tanski@polsl.pl

1 Division of Materials Processing Technology, Management and Computer Techniques in Materials Science, Institute of Engineering Materials and Biomaterials, Silesian University of Technology, Konarskiego Str 18A, 44-100 Gliwice, Poland treatment such as surface alloying, feeding and remelting [15-17].

Extremely wide-range of design capabilities in the automotive and aerospace industries provides modern light metal alloys. The use of aluminum or magnesium alloys as components for cars and planes allows for significant weight reduction and thus reduces fuel consumption and operating costs [7, 11, 12, 14-16]. Aluminum alloys are characterized by low density, high electrical and thermal conductivity, high corrosion resistance as well as the impact strength does not decrease when the temperature drops. The disadvantage of aluminum and magnesium alloys is low hardness and abrasion resistance [12]. Improvements to the above properties are often achieved by the surface treatment that allows for obtaining hard and abrasion-resistant surface layer to increase the utility of these materials in new engineering applications. Coatings of this type are obtained as a result of such treatment as surfacing, flame sprayed coatings, detonation sprayed coatings and laser remelting, feeding or alloying $[2,4,10,16]$.

In light of the research, an attempt was made to obtain a layer on the surface of aluminum with magnesium alloy as a result of surface treatment with the use a fiber laser. The use of a fiber laser with rectangular spot gives possibilities 
to obtain surface layer that is characterized by a uniform distribution of introduced elements, short time of heat source interaction on the workpiece, and the possibility of introducing a very wide range of alloy elements $[18,19]$. During the laser surface treatment of the aluminum alloy a mixture of nickel and chromium powders was introduced. Preliminary studies and review of the literature have shown significant influence of intermetallic phases on the aluminum alloys properties. The use of $\mathrm{Cr}$ and $\mathrm{Ni}$ powders during aluminum laser alloying allows for obtaining intermetallic phases that significantly increase the strength properties and wear resistance of the treated surface, increasing the weight of the workpiece slightly.

The goal of this study was focused on fiber laser alloying aluminum alloy AlMg5Si2Mn by a mixture of two powders $(\mathrm{Cr}$ and $\mathrm{Ni})$ and evaluate the resulted surface microstructure and properties, in particular, hardness and abrasion resistance.

\section{Experimental procedure}

The research involved laser surface treatment of aluminum alloy. Surface treatment was performed on fiber Ytterbium laser system YLS-4000 with a wavelength of $\lambda=1070 \mathrm{~nm}$. The maximum power of the laser beam was $4 \mathrm{~kW}$. Laser head was mounted on a 6-axis robot REIS RV30-26 coupled with a tilt-and-swivel positioning system. The laser alloying process was conducted in a shielding gas atmosphere of argon served with two independent nozzles. The first nozzle tilted at an angle of $30^{\circ}$ from the sample plane while the second is at 90 degrees. The task of the first nozzle was to provide an alloying powder in the liquid lake area. The protective gas pressure in the first nozzle determined the rate of feeding of the powder in the volume of the liquid metal. The second nozzle provided protective gas throughout the laser process. Its task was to protect the liquid metal from air damaging. The gas

Table 1 Parameters using during the laser alloying

\begin{tabular}{ll}
\hline Laser beam power, $\mathrm{kW} /$ dimension of laser beam & $3 \mathrm{~kW} / 3 \times 3 \mathrm{~mm}$ \\
\hline Shielding gas, $1 / \mathrm{min}$ & \\
Firs nozzle & 8 \\
Second nozzle & 15 \\
Powder feeding g/min & 4.5 \\
Sample initial temperature, $\mathrm{K}$ & 298 \\
Laser beam scanning rate, $\mathrm{m} / \mathrm{min}$ & 0.5 \\
\hline
\end{tabular}

stream was of less point in this case. Gas dispersion allowed the whole sample to be protected without affecting the stream from the powder feeder. Parameters used during laser alloying are presented in Table 1.

The investigation was carried out on cast aluminum alloy with magnesium and silicon EN AC-AlMg5Si2Mn. The chemical composition of the applied aluminum alloy is shown in Table 2. To improve the mechanical properties of the surface layer during the laser treatment in area of liquid aluminum, the metallic powder $\mathrm{Cr}-\mathrm{Ni}$ (the mix of $\mathrm{Cr}$ and $\mathrm{Ni}$ powder $50 / 50 \%$ ) was introduced. The grain size of the applied powder was in the range of $60-130 \mu \mathrm{m}$. To completely eliminate moisture, which, as indicated in preliminary studies, was primarily responsible for harmful porosity found on the alloyed surface, the $\mathrm{Cr}-\mathrm{Ni}$ powder was dried before the process in a dryer for $24 \mathrm{~h}$ at $250^{\circ} \mathrm{C}$. The porous structure allowed better bonding of the undissolved particles to the base material in the volume of the layer and facilitated their dissolution during the melt. The morphology of the applied powder is shown in Fig. 1.

Samples before surface laser alloying were ground mechanically on laboratory LabPol5 Struers grinding machine. For surface preparation, three sandpaper of grades $60-15 \mu \mathrm{m}$ has been used. After grinding, to remove the silicon carbide particles from the abrasive paper, the samples were purified in an ultrasonic scrubber (maximum intensity, at $45^{\circ} \mathrm{C}$ for $25 \mathrm{~min}$.). As a washing solution, methyl alcohol was used. Next, the prepared sample surface was covered with a flux and ethyl alcohol (average thickness of flux $1 \mathrm{~mm}$ ). To remove alcohol and water from the surface, the covered sample was dried on a hot plate at $100{ }^{\circ} \mathrm{C}$ in $60 \mathrm{~min}$. Application of welding flux layer on consisting of a mixture of lithium chloride the top surface of samples allowed to dissolve metal oxides formed on the surface of the aluminum substrate and significantly increased the adsorption of laser radiation by a processed material.

The microstructure of the analyzed layer was examined by light microscope Axio Observer Zeiss and a scanning electron microscope Zeiss Supra 35 (SE, BSE). Analysis of the chemical composition and phases occurring in the layer was carried out using a scattered X-ray detector and EBSD. The surface topography was observed using a stereomicroscope SteREO Discovery Zeiss. Surface observations were made at a magnification of $25 \times$ to $50 \times$ using ring and side illuminators.

The surface hardness measurements were performed using a Rockwell test in HRF scale. Micro-hardness on the layer cross-section was measured by the Vickers microhardness test with a force of $300 \mathrm{gf}(2.94 \mathrm{~N})$.

The wear resistance studies of surface layer were performed using a ball-on-disk test. Test parameters are shown
Table 2 The chemical composition of investigated aluminum alloy-ENACAlMg5Si2Mn

\begin{tabular}{lllllllll}
\hline Elements & $\mathrm{Fe}$ & $\mathrm{Si}$ & $\mathrm{Mn}$ & $\mathrm{Ti}$ & $\mathrm{Cu}$ & $\mathrm{Mg}$ & $\mathrm{Zn}$ & $\mathrm{Al}$ \\
\hline AlMg5Si2Mn & 0.12 & 1.9 & 0.58 & 0.009 & 0.005 & 5.17 & 0.01 & Rest \\
\hline
\end{tabular}



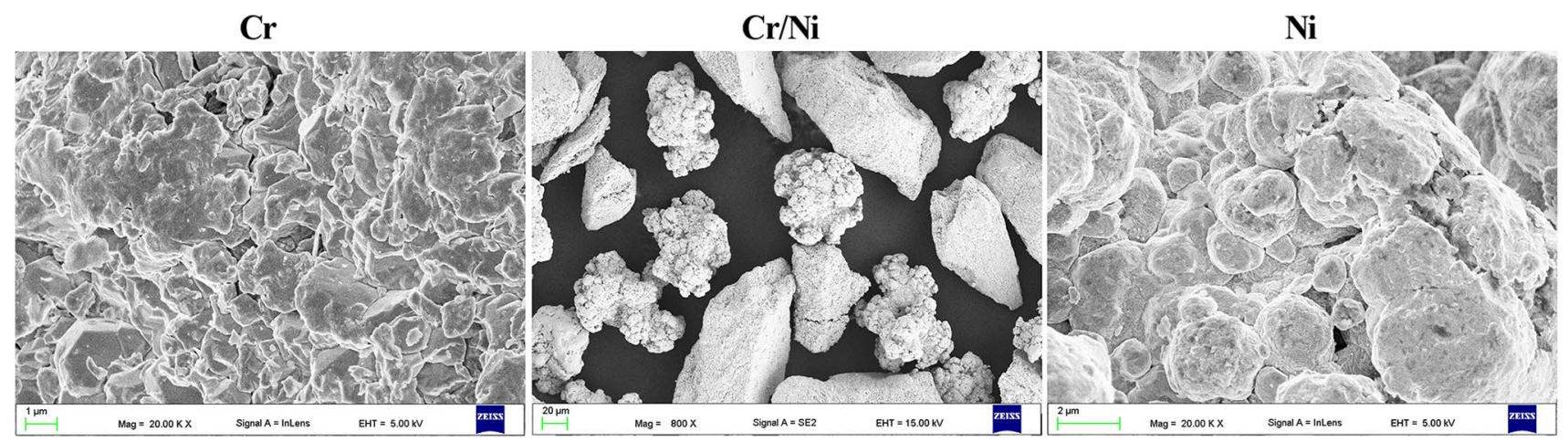

Fig. 1 The morphology of $\mathrm{Cr} / \mathrm{Ni}$ powder applied to aluminum laser surface alloying

Table 3 The ball-on-disk wear test parameters

\begin{tabular}{lllll}
\hline Load, $N$ & $\begin{array}{l}\text { Linear speed, } \\
\mathrm{cm} / \mathrm{s}\end{array}$ & Distance, $\mathrm{m}$ & Radius, $\mathrm{mm}$ & $\begin{array}{l}\text { Counter } \\
\text { specimen }\end{array}$ \\
\hline 5 & 10 & 100 & 2.5 & $\mathrm{Ball}-\mathrm{ZrO}_{2}$ \\
\hline
\end{tabular}

in Table 3. The wear rate was analyzed on the basis of the depth and volume of the trace. The wear tracks after the test were measured with a profilometer, Sutronic 25 TaylorHobson. During surface roughness, measured by profilometer, Gaussian filter of 0.8 was applied. The wear track was analyzed using a scanning electron microscope to reveal rifts and deformation of the surface layer and evaluate wear mechanism. During the tribological test was also registered friction coefficient between a tested surface and ceramic counter specimen $\left(\mathrm{ZrO}_{2}\right)$. The friction coefficient analysis allowed for the disclosure of changes occurring during the test such as, the peeling and removing of the material particles from the surface.

\section{Results and discussion}

Stereoscopic and electron microscope observations did not show cracks or porosity on the alloying surface. Based on the EDS analysis in the scanning electron microscope, several undissolved powder particles are disclosed on the surface of the layer. Also, there was no observed porosity or void around the undissolved (molten) particles.The powder was closely bound to the aluminum matrix. The vast majority of undissolved particles on the melting surface were chrome. The greater share of undissolved chromium was due to its higher melting point compared to nickel. Because at the design stage of the layer, the abrasive finishing allowance was applied, the undissolved particles on the surface did not take part during the abrasion test. The scale and oxide film was also removed from the surface by grinding before the ball-on-disk test. Layer surface topography is shown in Fig. 2. The average roughness of the layer was about $2.23 \mu \mathrm{m}$ (Fig. 3). In addition, the profiles analysis of the obtained layer measured with the Surtronic 25 contact profilometer did not show a significant variation in wave on the surface. The widest distance between the local extremities was $170 \mu \mathrm{m}$. This demonstrates the correct selection of scanning speed, power and protective gas stream, as well as the amount and rate of feed of the used powder during fiber laser fusion. The wave and roughness profile of the layer is shown in Fig. 3.

At the bottom of the resulting layer, a dendritic cell structure is disclosed. Simultaneously, as a result of rapid crystallization, significant grain refinement was obtained, which has a beneficial influence on the strength properties such as hardness as well as abrasion resistance (as has been proved-Fig. 10). It was not observed in solidification molten pool the defects in the form of cracks, voids or craters which could adversely affect the strength properties of the obtained layer [18, 19]. The transition zone between the substrate material and the obtained layer was less enriched in phases containing $\mathrm{Cr}$ and $\mathrm{Ni}$. Analysis on the light microscope did not reveal visible heat-affected zones. The AlMg5Si2Mn alloy structure is shown in Fig. 4a-c.

Maps of chemical distribution obtained by means of EDS detector has shown a significant increase of chromium and nickel concentration in the total melting volume. The average concentration of chromium in the layer area was $02.77 \%$ while nickel $02.37 \%$ at $(\mathrm{Cr}-05.09 \%$; $\mathrm{Ni}-04.91 \%$ wt.). In addition, the uniform distribution of introduced chemical elements during laser treatment was confirmed. At the same time, the refinement of magnesium and silicon-rich phases was revealed, which was due to rapid crystallization of the melting area (Fig. 4d-e).

Based on scanning-microscope analysis using the "EDS" $\mathrm{X}$-ray diffraction detector, numerous areas enriched in chromium and nickel are disclosed (Fig. 5). Detailed analysis using the "Electron Backscatter Diffraction Analysis" EBSD 

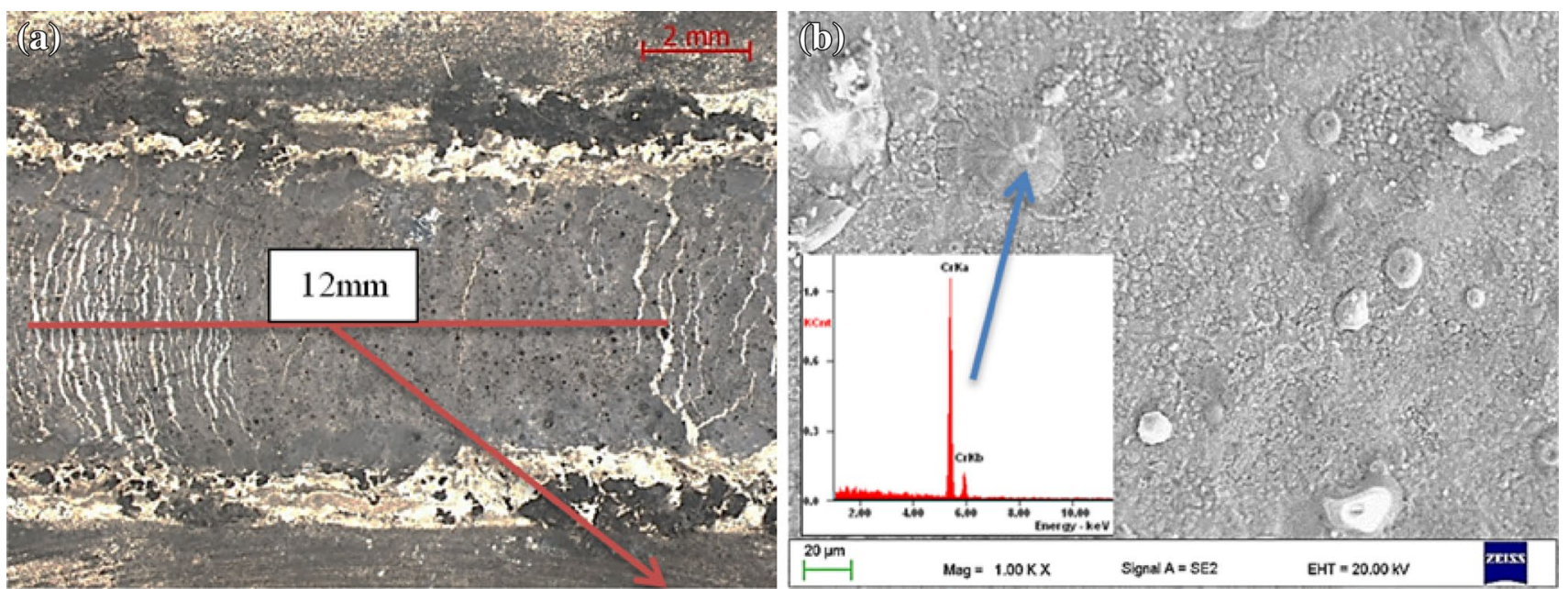

Fig. 2 Surface topography of the layers obtained during laser treatment at different magnifications; $\mathbf{a} \times 10, \mathbf{b} \times 25$

Fig. 3 Roughness and waviness profile curves of the surface layer

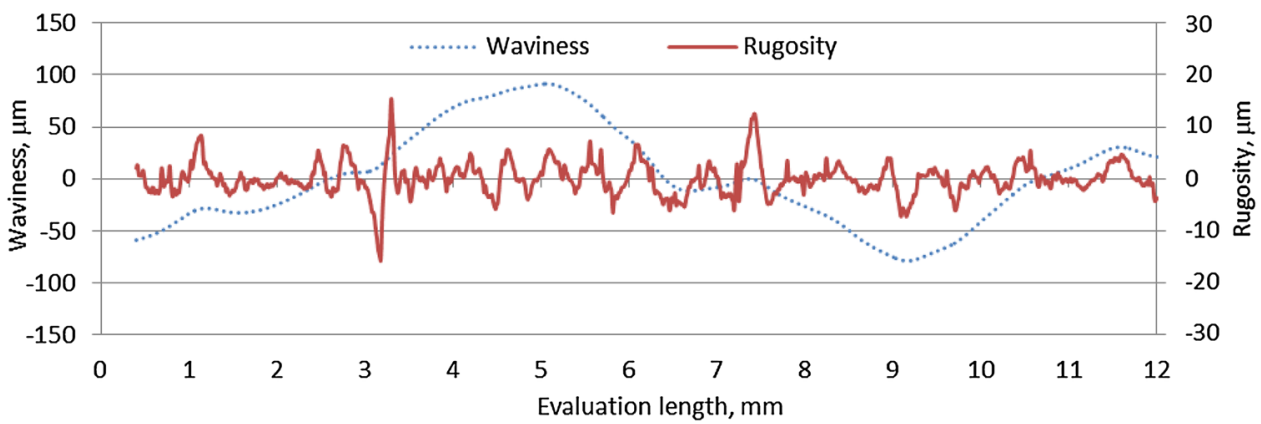

has shown a number of intermetallic phases resulting from laser alloying of aluminum $\left(\mathrm{Al}_{4} \mathrm{Ni}_{3}, \mathrm{Al}_{9} \mathrm{Cr}_{4}, \mathrm{Mg}_{3} \mathrm{AlNi}\right)$ evenly distributed across the entire melting area. In addition, many phases derived from a primary material such as $\mathrm{Mg}_{2} \mathrm{Si}$ have been observed in the melting area. Moreover, the analysis showed the highest proportion of intermetallic chrome-rich phases in the obtained layer (Fig. 6).

The wear test product (powder on the wear track surface) was much finer when compared to the test result of base material. Fragmentation was caused by an increase in hardness and the occurrence of numerous intermetalic phases (rich in $\mathrm{Cr}$ and $\mathrm{Ni}$ ) in layer volume. In case of an untreated alloy, numerous large fragments (flakes) extracted and detached from the tested surface was observed (Fig. 7b, e).

The wear track on the aluminum alloy surface in many places was plastically degraded and extracted. It should be emphasized that this is the typical wear of this material type. In the case of the wear track obtained on the layer, only few breach and gap in the material were disclosed. The edges of the fracture were sharp as evidenced by partial plasticity reduction. In both cases, the dominant wear mechanism was furrowing. In addition, it was not observed on the surface of wear track, as well as in wear product (powder and flakes) oxidized particles indicating overheating or excessive heat generation (the temperature was not measured during the test) (Fig. 7c, f).

On the zircon sphere surface (ceramic counterspecimen), after tribological test of the layer, fine scratches and traces of substrate material was revealed (Fig. 7d). In the case of the counter-sample after the aluminum alloy study, numerous built-up of substrate material, almost completely covering the surface of the ball, are disclosed (Fig. 7a).

For the first $0.2 \mathrm{~m}$, the friction coefficient (FC) in both cases did not exceed 0.2 (no scratching of the surface). After about $0.2 \mathrm{~m}$, a significant increase in the friction coefficient was observed to about 0.79 (layer) and 0.73 (aluminum alloy). Initial FC stabilization up to 0.4 for $\mathrm{AlMg} 5 \mathrm{Si} 2 \mathrm{Mn}$ and 0.42 (layer) occurred after about $15 \mathrm{~m}$. At that time, significant fluctuations in coefficients due to scratching of the surface and built-up of substrate material on the counterspecimen surface (Fig. 8).

In the case of the layer, a higher FC is revealed than in the case of unworked $\mathrm{Al}$ alloy. This phenomenon was triggered by the regular shearing of an aluminum film from 
(a)

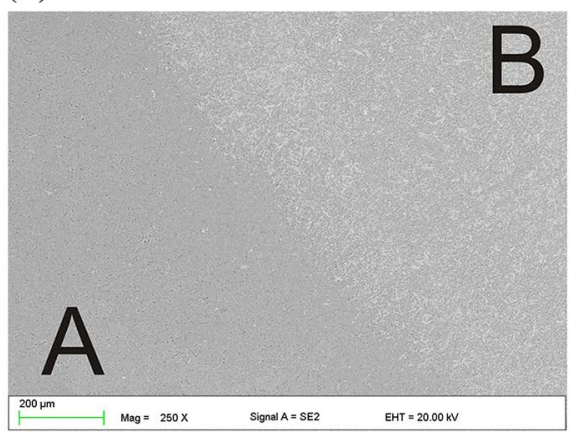

(d)

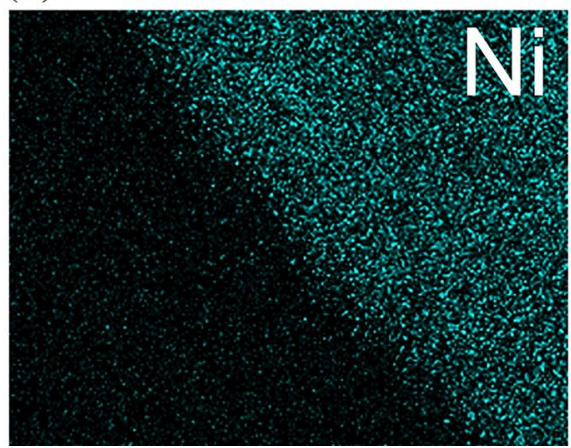

(b)

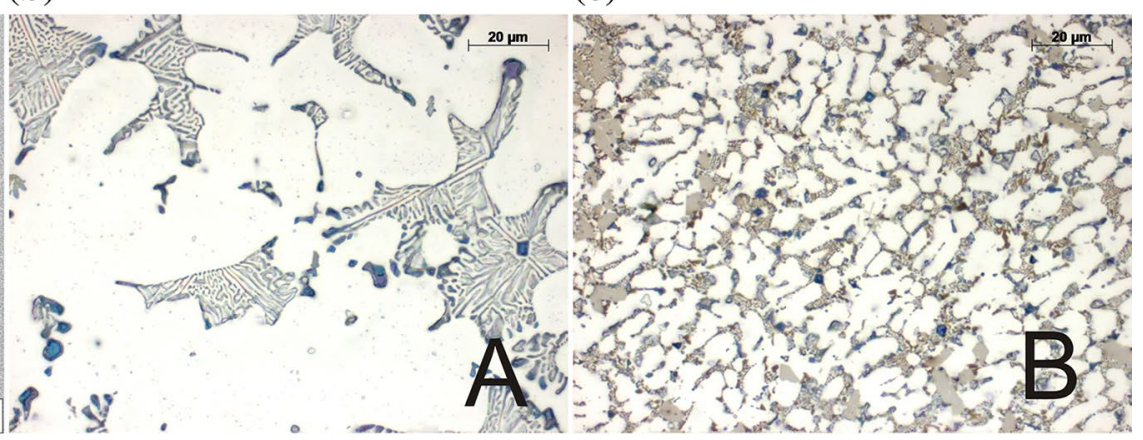

(e)

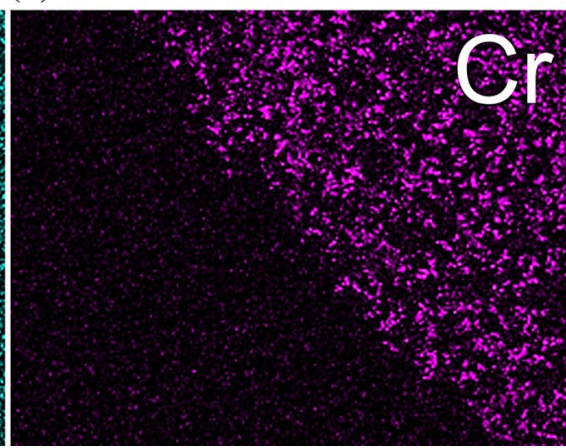

(c)

(f)

Fig. 4 a Structure of AlMg5Si2Mn alloy (A-based material; B-alloyed zone) before $\mathbf{b}$ and after laser surface treatment (c) as well as map of distribution: nickel (d), chromium (e) and magnesium (f)

(a)

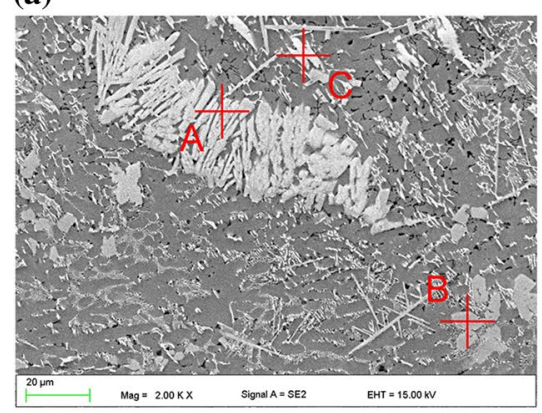

(b)

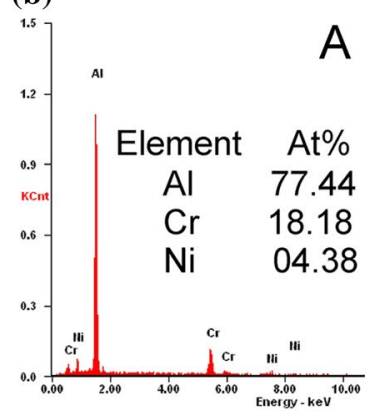

(c)

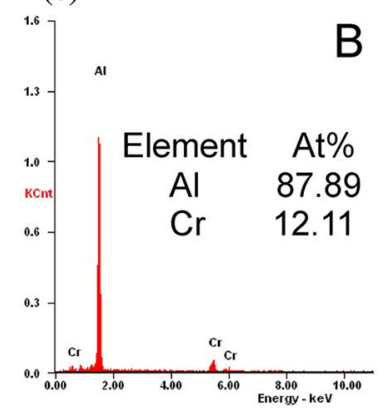

(d)

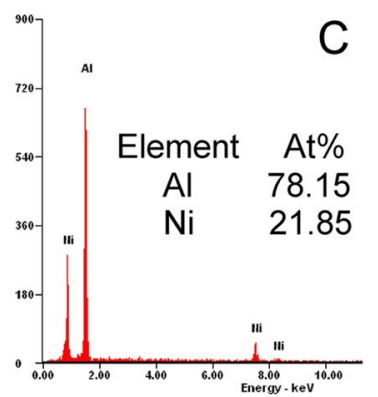

Fig. 5 Result of EDS analysis in point: a structure of alloying layer, $\mathbf{b}-\mathbf{d}$ chemical composition in analyzed point

the ceramic ball surface by the hard intermetallic phase obtained during the laser alloying. In addition, shear stress caused slightly higher coefficient deviations than in the case of the based material. The largest changes in the coefficient recorded for the underlying material were due to the creation of aluminum film on the counter-speciment surface and the removal (pull-off) of aluminim alloys flakes from the substrate. In both cases, a stabilization of the friction coefficient was observed after about $50 \mathrm{~m}$. Only in the case of based alloy after $89 \mathrm{~m}$ revealed visible peak (point friction coefficient) (Fig. 8). Most likely, this was due to the detachment of part of the film from the ceramic surface (Fig. 7a).
In the case of the layer, there was also a much smaller plastic deformation at the edges of the wear track with respect to the based aluminum alloy. The average plastic deformation height on the surface layer was $4.48 \mathrm{~mm}$ and was about $33 \%$ lower with respect to the plastic deformation obtained after the aluminum alloy abrasion test. In addition, the surface area of obtained deformation on the surface layer was about $970 \mathrm{~mm}^{2}$ smaller than that of the aluminum alloy test. Reducing plasticity is due to the presence of precipitates and grain refinement. Analysis of the wear track measured using a contact profilometer revealed a significant increase in abrasion resistance of chromium and nickel rich layer. 
(a)

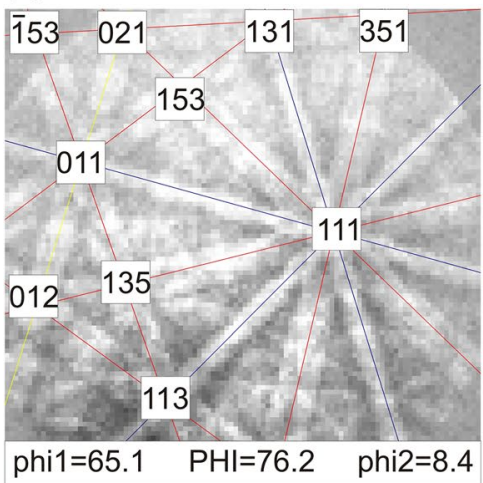

(b)

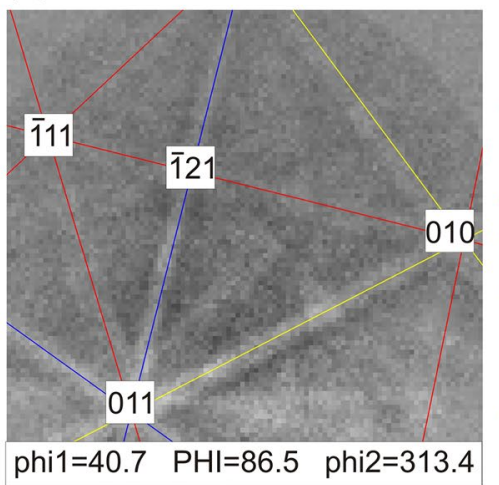

(c)

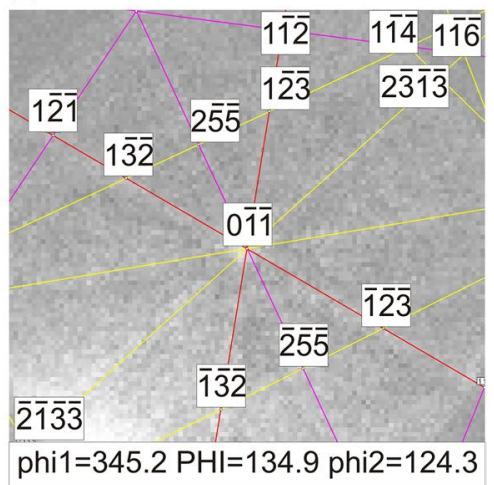

Fig. 6 Results of EBSD analysis: $\mathbf{a} \mathrm{Al}_{4} \mathrm{Ni}_{3}, \mathbf{b} \mathrm{Al}_{9} \mathrm{Cr}_{4}$ and $\mathbf{c} \mathrm{Mg}_{3} \mathrm{AlNi}$
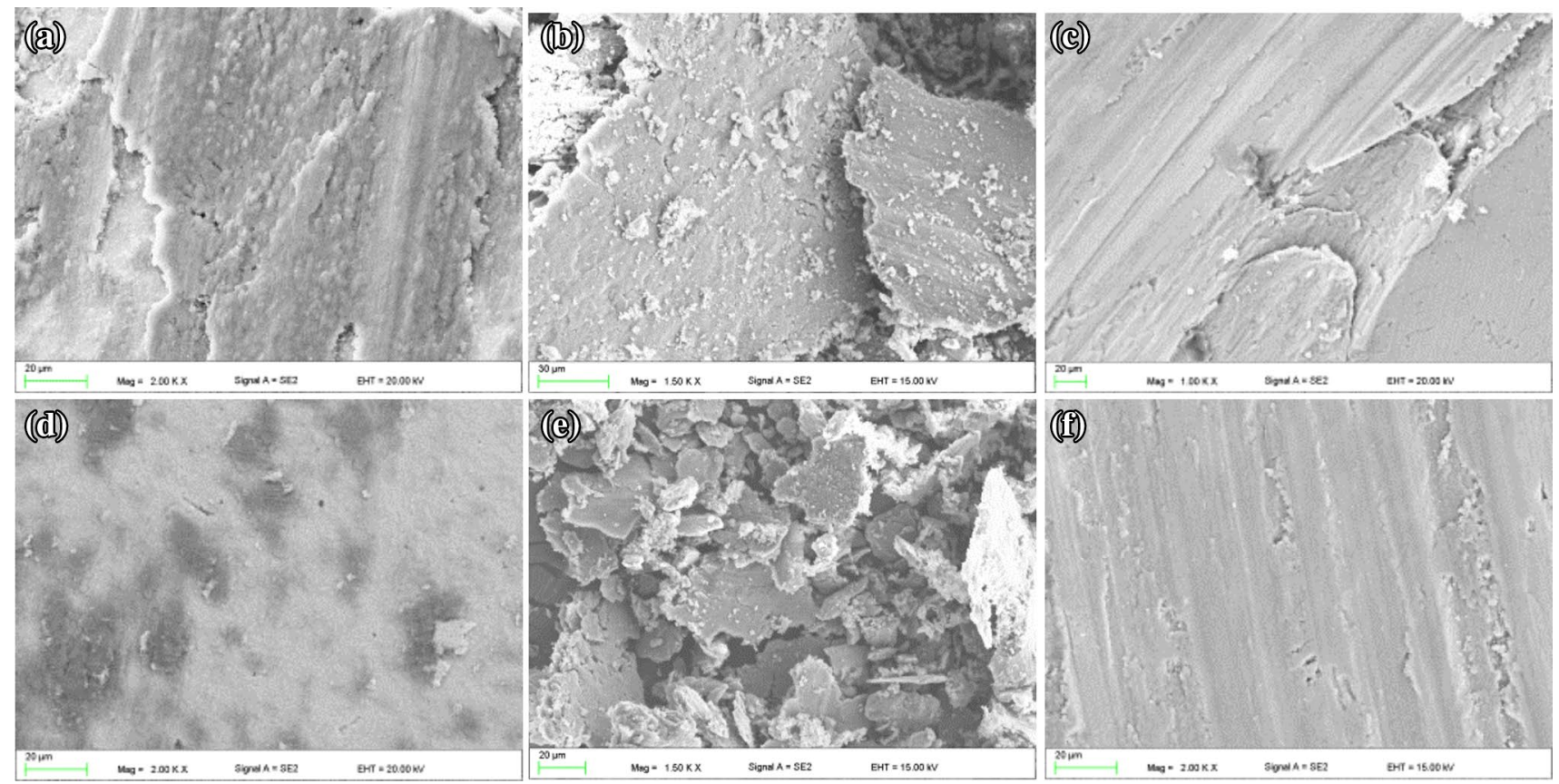

Fig. 7 Result of tribological test: a, $\mathbf{d}$ coutersample after tribological test of a aluminum alloy, $\mathbf{d}$ layer; $\mathbf{b}$, e powder (flkes) obtained during the test $\mathbf{b}$ aluminum alloy, $\mathbf{e}$ layer and $\mathbf{c}, \mathbf{f}$ wear truck after the test of $\mathbf{c}$ aluminum alloy, $\mathbf{f}$ layer

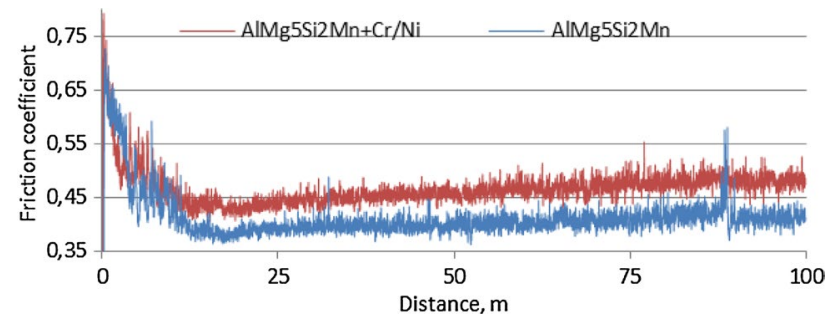

Fig. 8 The friction coefficient during ball-on-disk wear test
The volume of a crater in the case of layer is $46 \%$ lower with respect to the alloy without surface treatment. The results of the dimension measurement of wear track are shown in Table 4 and Fig. 9.

Measurements of mechanical properties revealed a significant hardness increase in the melting area at a depth of about $3 \mathrm{~mm}$ from the surface of the layer. The average micro-hardness in the melting area was about 25HV higher than the substrate material and was $109 \mathrm{HV}_{0.3}$ (Fig. 10b). A small scatter of hardness over the entire depth of the layer shows that the entire melting area is evenly reinforced. In addition, hardness measurement on the HRF scale showed a significant increase in hardness on the top of the layer. In 
Table 4 Dimension and roughness of wear track

\begin{tabular}{|c|c|c|c|c|c|c|c|c|}
\hline \multirow[t]{2}{*}{ Substrate } & \multicolumn{3}{|c|}{ Dimensions of plastic deformation } & \multicolumn{4}{|c|}{ Dimensions of wear track } & \multirow{2}{*}{$\begin{array}{l}\text { Roughness } \\
\mathrm{Ra}(\mu \mathrm{m})\end{array}$} \\
\hline & Height, $\mu \mathrm{m}$ & Width, $\mu \mathrm{m}$ & Surface area, $\mu \mathrm{m}^{2}$ & Depth, $\mu \mathrm{m}$ & Width, mm & Surface area, $\mu \mathrm{m}^{2}$ & Volume, $\mathrm{mm}^{3}$ & \\
\hline Aluminum alloy & 13.5 & 109.2 & 1280.32 & 31.5 & 0.92 & 17344.23 & 0.4325 & 1.62 \\
\hline Layer & 4.48 & 53.23 & 310.13 & 25.4 & 0.78 & 8229.17 & 0.2057 & 0.99 \\
\hline
\end{tabular}

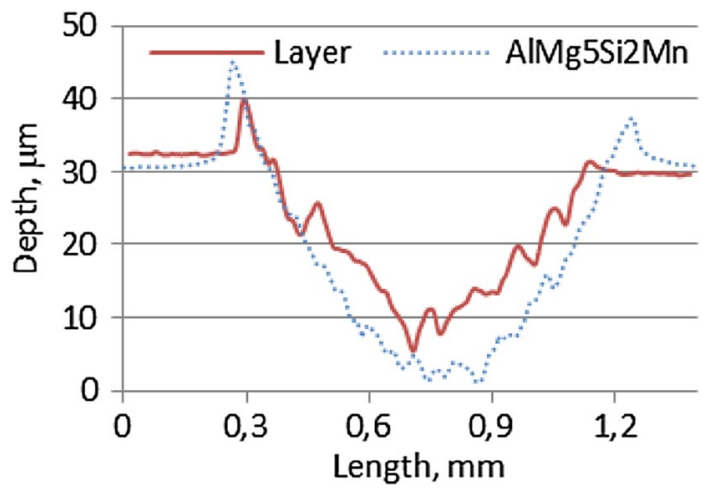

Fig. 9 Wear track after tribological test ball-on-disk

the case of the substrate material, the average hardness was about 77HRF while the hardness of the layer was about 99 (Fig. 10a). Such a significant increase in the hardness of the layer was due to numerous $\mathrm{Al}_{4} \mathrm{Ni}_{3}, \mathrm{Al}_{9} \mathrm{Cr}_{4}, \mathrm{Mg}_{3} \mathrm{AlNi}$ phases occurring in the layer after the laser treatment as well as the grain refinement and phases derived from the based material. The results of hardness measurements are shown in Fig. 10.

\section{Conclusion}

As demonstrated in this study, the use of surface treatment with an optical fiber laser makes it possible to significantly improve the mechanical properties as well as wear resistance of the AlMg5Si2Mn alloy tested, thereby contributing to its attractiveness in many engineering fields of possible applications. Laser surface treatment of aluminum alloy with the use of metalic powder $\mathrm{Ni} / \mathrm{Cr}(50 / 50 \% \mathrm{wt}$.) allowed to obtain a homogeneous layer tightly bound to the substrate, without voids, cracks and porosity. Both the shape and the face of remelting means that they find the optimal process parameters. Observations with light and scanning microscope has not revealed the heat-affected zone (that is very narrow and hard to estimate precisely).

Based on scanning-microscope analysis using the "EDS" $\mathrm{X}$-ray diffraction detector, numerous areas enriched in chromium and nickel are disclosed (Fig. 5). Detailed analysis using the "Electron Backscatter Diffraction Analysis" EBSD has shown a number of intermetallic phases resulting from laser alloying of aluminum $\left(\mathrm{Al}_{4} \mathrm{Ni}_{3}, \mathrm{Al}_{9} \mathrm{Cr}_{4}, \mathrm{Mg}_{3} \mathrm{AlNi}\right)$ evenly distributed across the entire melting area. In addition, many phases derived from a primary material such as $\mathrm{Mg}_{2} \mathrm{Si}$ have been observed in the melting area.

The use of surface treatment has allowed for a significant increase in hardness. The average hardness of the layer was 99HRF and was $22 \mathrm{HRF}$ higher concerning to the based material. Measurements made on the cross section showed a uniform increase in hardness over the entire depth of the layer. The average microhardness of the layer was $109 \mathrm{HV}_{0.3}$ and was about $25 \mathrm{HV}_{0.3}$ higher than the substrates material. On the tribological test basis, a significant increase in abrasion resistance of $\mathrm{Cr}$ and $\mathrm{Ni}$-enriched surfaces has been demonstrated. The wear track volume obtained during laser treatment layer was $0.2057 \mathrm{~mm}^{3}$ and was about $46 \%$ less than the crater on the surface of the aluminum alloy without
Fig. 10 Results of hardnes measurments-HRF scale (a) and (b) microhardnes during the cros section of obtained layerHV scale

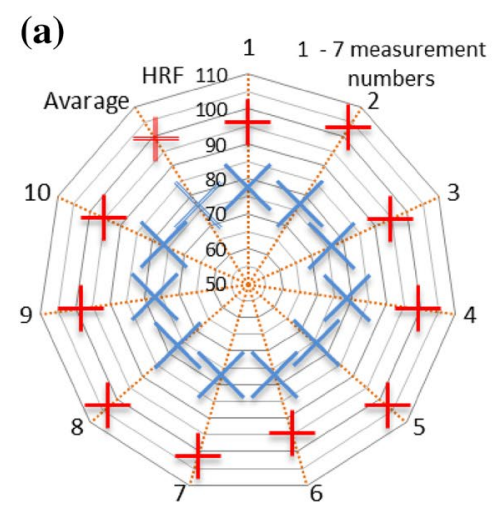

$+\mathrm{AlMg} 5 \mathrm{Si} 2 \mathrm{Mn}+50 \mathrm{Cr} 50 \mathrm{Ni} \quad \times \mathrm{AIMg} 5 \mathrm{Si} 2 \mathrm{Mn}$

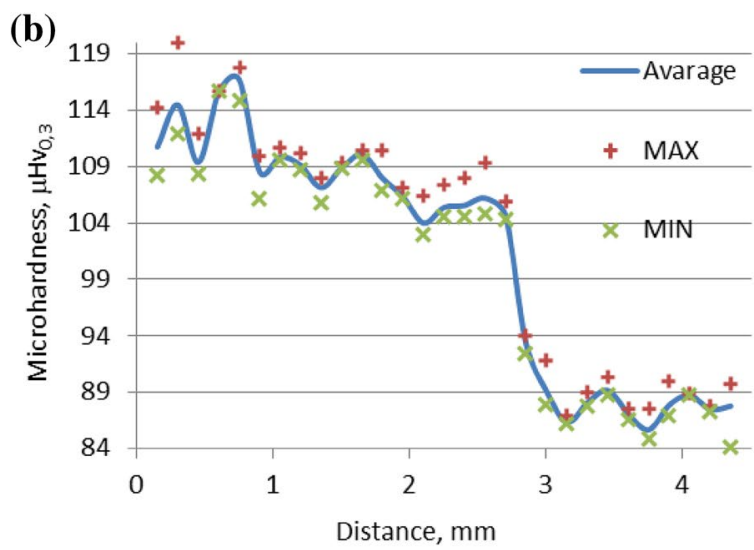


surface treatment. Laser alloying caused partial reduction in plasticity of the material. The average surface area of the plastic deformation after the "ball on disk" test on the layer was about $24 \%$ lower than the base aluminum alloy. The resulting layer greatly enhances the mechanical properties of the aluminum surface and thus increases the resistance to abrasion.

Acknowledgements The publication was partially financed by statutory grant from Faculty of Mechanical Engineering, The Silesian University of Technology for year $2017 \mathrm{Nr}$ 10/010/RGJ17/0145. This publication was financed by the Ministry of Science and Higher Education of Poland as the statutory financial grant of the Faculty of Mechanical Engineering SUT in 2017.

Open Access This article is distributed under the terms of the Creative Commons Attribution 4.0 International License (http://creativeco mmons.org/licenses/by/4.0/), which permits unrestricted use, distribution, and reproduction in any medium, provided you give appropriate credit to the original author(s) and the source, provide a link to the Creative Commons license, and indicate if changes were made.

\section{References}

1. S. Wojciechowski, New trends in the development of mechanical engineering materials. J. Mater. Process. Technol. 106(1-3), 230-235 (2000)

2. T. Tanski, K. Labisz, K. Lukaszkowicz, Characterisation and properties of hybrid coatings deposited onto magnesium alloys. Surf. Eng. 30/12, 927-932 (2014)

3. D. Janicki, Laser cladding of Inconel 625-based composite coatings reinforced by porous chromium carbide particles., Opt. Laser Technol. 94 6-14, (2017). https://doi.org/10.1016/j.optla stec.2017.03.007

4. A. Lisiecki, J. Piwnik, Tribological characteristic of titanium alloy surface layers produced by diode laser gas nitriding. Arch. Metall. Mater. 61, 543-552 (2016). https://doi.org/10.1515/amm-20160094 No 2

5. M. Adamiak, B. Tomiczek, J. Górka, A. Czupryński, Joining of the AMC composites reinforced with $\mathrm{Ti} 3 \mathrm{Al}$ intermetallic particles by resistance butt welding. Arch. Metall. Mater. 61(iss. 2A), 847-852 (2016)

6. A. Sliwa, J. Mikula, K. Golombek, T. Tański, W. Kwaśny, M. Bonek, Z. Bytan, Prediction of the properties of PVD/CVD coatings with the use of FEM analysis. Appl. Surf. Sci. 388(1), 281287 (2016)
7. L.A. Dobrzański, M. Macek, B. Tomiczek, P.M. Nuckowski, A.J. Nowak, The influence of the dispersion method on the microstructure and properties of MWCNTs/AA6061 composites. Arch. Metall. Mater. 61(iss. 2B), 1229-1234 (2016)

8. Z. Brytan, M. Bonek, L.A. Dobrzanski, W. Pakieła, Surface layer properties of sintered ferritic stainless steel remelted and alloyed with FeNi and Ni by HPDL laser. Adv. Mater. Res. 291-294, 1425-1428 (2011)

9. E. Torres, D. Ugues, Z. Brytan, M. Perucca, Development of multilayer coatings for forming dies and tools of aluminium alloy from liquid state. J. Phys. D: Appl. Phys. 42(10), 1-7, Article 105306 (2009)

10. D. Janicki, M. Musztyfaga-Staszuk, Direct Diode Laser Cladding of Inconel 625/WC Composite Coatings, Strojniški vestnik. J. Mech. Eng. 62/6, 363-372, (2016). https://doi.org/10.5545/ sv-jme.2015.3194

11. L.A. Dobrzanski, T. Tanski, J. Trzaska, Optimization of heat treatment conditions of magnesium cast alloys. Mater. Sci. Forum 638-642, 1488-1493 (2010)

12. T. Tanski, P. Snopinski, W. Pakiela, W. Borek, K. Prusik, S. Rusz, Structure and properties of AlMg alloy after combination of ECAP and post-ECAP ageing. Arch. Civil Mech. Eng. 16(3), 325-334 (2016)

13. M. Król, P. Snopiński, B. Tomiczek, T. Tański, W. Pakieła, W. Sitek, Structure and properties of an Al alloy in as-cast state and after laser treatment. Proc. Estonian Acad. Sci. 65/2, 107-116 (2016). https://doi.org/10.3176/proc.2016

14. T. Tanski, P. Snopinski, W. Borek, Strength and structure of AlMg3 alloy after ECAP and post-ECAP processing. Mater. Manuf. Process. 32/12, 1368-1374 (2017)

15. A. Dobrzanska-Danikiewicz, T. Tanski, I. Domagala-Dubiel, Unique properties, development perspectives and expected applications of laser treated casting magnesium alloys. Arch. Civil Mech. Eng. 12(3), 318-326 (2012)

16. K. Labisz, T. Tanski, D. Janicki, W. Borek, K. Lukaszkowicz, L.A Dobrzanski, Effect of laser feeding on heat treated aluminium alloy surface properties. Arch. Metall. Mater. 61(2), 741-746 (2016)

17. K. Labisz, T. Tański, Z. Brytan, W. Pakieła, M. Wiśniowski, Aluminium surface treatment with ceramic phases using diode laser. Appl. Phys. A Mater. Sci. Process. 122/7, 1-10, (2016). https:// doi.org/10.1007/s00339-016-0180-y

18. W. Pakieła, L.A. Dobrzański, K. Labisz, T. Tański, K. Basa, M. Roszak, The effect of laser surface treatment on structure and mechanical properties aluminium alloy ENAC-AlMg9. Arch. Metall. Mater. (2016). https://doi.org/10.1515/amm-2016-0221

19. W. Pakieła, T. Tański, Z. Brytan, K. Labisz, The influence of laser alloying on the structure and mechanical properties of AlMg5Si2Mn surface layers. Appl. Phys. A-Mater. Sci. Process. 122/4, 1-9, (2016). https://doi.org/10.1007/s00339-016-9834-z 